\title{
Finite Element Simulation and Construction Technology Research of Cement-Emulsified Asphalt Cold Recycling System
}

\author{
Junxiao $\mathrm{LI}^{1,{ }^{*}}$, Wei $\mathrm{FU}^{2}$ and Xiaobo $\mathrm{YIN}^{3}$ \\ ${ }^{1}$ Institute of Oceanographic Instrmentation, Qilu University of Technology (Shandong Academy of Sciences), Shandong Provincial \\ Key Laboratory of Marine monitoring instrument equipment technology, National Engineering and Technological Research Center of \\ Marine Monitoring Equipment, Qingdao 266001, China \\ 2 Dept. of No.2 sanatorium, Navy Qingdao No.1 Sanatorium of PLA, Qingdao 266001, China \\ ${ }^{3}$ Zhuhai Dacheng Engineering Testing Co. Ltd, Zhuhai 519000, China
}

\begin{abstract}
The force model of pavement structure is established. In order to investigate the force on pavement when the ratio and thickness of cold recycled pavement vary, three concrete pavement structures, material parameters and vehicle load parameters are designed. By finite element analysis, type 2 pavement structure make the cold-regenerative pavement structure anti-XY surface shear stress, anti-Z compressive stress and anti-Z deformation three aspects are kept in a reasonable range, and it is considered that the cold regenerative pavement structure type 2 is the best. Type 2 is specifically composed of $8 \mathrm{~cm}$ new asphalt surface layer $+20 \mathrm{~cm}$ no stabilized soil regeneration base $+20 \mathrm{~cm}$ stabilized soil regeneration base + original road soil base. The results of this paper can provide some reference for the actual design of emulsified asphalt cold regeneration construction process.
\end{abstract}

\section{Introduction}

In china, the total number of highways was $4,773,500$ $\mathrm{km}$ by the end of 2017. About 2.2 million tonnes of recycled asphalt pavement material (RAP) is generated annually, based on $12 \%$ of high-grade road surface maintenance ${ }^{[1,2,3]}$. If RAP is abandoned directly, it will not only cause pollution to the environment, but also be a serious waste of resources. Therefore, it is very necessary to study RAP regeneration technology. Emulsified asphalt cold regeneration technology is a kind of asphalt mixture regeneration technology which can reuse RAP to make the recycled mixture have good workability and can be constructed at room temperature ${ }^{[4]}$. This is a cost-effective way to maintain and upgrade asphalt pavement. At present, the research progress on emulsified asphalt cold regeneration is very fast at home and abroad ${ }^{[5,6]}$.

The cold regeneration of emulsified asphalt is affected by many factors. In this paper, the force model of pavement structure is established. In order to investigate the force on pavement when the ratio and thickness of cold recycled pavement vary, three concrete pavement structures, material parameters and vehicle load parameters are designed. By finite element analysis, type 2 pavement structure make the cold-regenerative pavement structure anti-XY surface shear stress, anti- $Z$ compressive stress and anti- $Z$ deformation three aspects are kept in a reasonable range, and it is considered that the cold regenerative pavement structure type 2 is the best. Type 2 is specifically composed of $8 \mathrm{~cm}$ new asphalt surface layer $+20 \mathrm{~cm}$ no stabilized soil regeneration base $+20 \mathrm{~cm}$ Stabilized soil regeneration base + original road soil base. The results of this paper can provide some reference for the actual design of emulsified asphalt cold regeneration construction process.

\section{Parameter setting and finite element model}

\subsection{The basic assumptions}

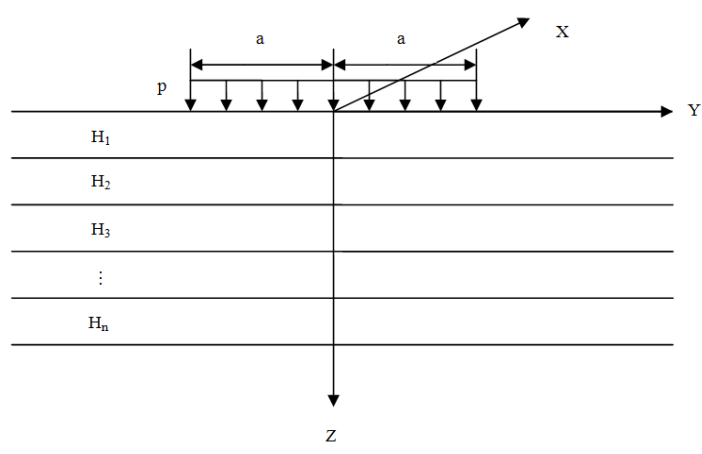

Fig. 1. Pavement stress model

(1) All layers are homogeneous linear elastic materials, and the elastic modulus E and Poisson's ratio are used to characterize.

(2) The contact between the layers is completely continuous.

\footnotetext{
* Corresponding author: caike0501@163.com
} 
(3) The foundation is a elastic half-space body, and It is infinite in both horizontal and vertical downward directions.

(4) The thickness of each layer on the foundation is limited, but the horizontal direction is infinite.

(5) The load on the road meter is only vertical static load, and the load axis is uniformly distributed. The force model of road surface is shown in Fig. 1.

\subsection{Cold recycling mixtures system structure layer and combination design}

There are many types of pavement structure. As shown in Figure 2, after cold recycling simplify the pavement structure to New asphalt pavement + No stabilized soil regeneration base + Stabilized soil regeneration base + Original roadbed.

\begin{tabular}{c}
\hline New asphalt pavement \\
\hline No stabilized soil regeneration base \\
Stabilized soil regeneration base
\end{tabular} Cold regeneration layer

Original roadbed

Fig. 2. Pavement stress model.

As shown in Table 1, three types of cold recycled pavement structures are designed in order to investigate the force on pavement when the ratio and thickness of cold recycled pavement vary.

Table 1. The thickness of each layer under the structure of three types of cold regenerative pavement

\begin{tabular}{|c|c|c|c|}
\hline \multirow{2}{*}{ Structural Layer } & Type 1 & Type 2 & Type 3 \\
\cline { 2 - 4 } & \multicolumn{3}{|c|}{ Thickness /cm } \\
\hline New asphalt pavement & 8 & 8 & 8 \\
\hline $\begin{array}{c}\text { No stabilized soil } \\
\text { regeneration base }\end{array}$ & 10 & 20 & 30 \\
\hline $\begin{array}{c}\text { Stabilized soil } \\
\text { regeneration base }\end{array}$ & 30 & 20 & 10 \\
\hline Original roadbed & - & - & - \\
\hline
\end{tabular}

\subsection{Parameter setting}

\subsubsection{Formatting author names and author affiliations}

As shown in Fig. 3, under single wheel loading, the ground area of the vehicle tire can be approximately a rectangle and two semicirons with radius of $0.3 \mathrm{~L}$. The tire pressure $\mathrm{P}$ is regarded as uniform load. $\mathrm{L}$ is the load acting length. A is the loading area, and it can be calculated by dividing the load on each tire by the tire pressure.

$$
L=\sqrt{\frac{A}{0.5227}}
$$

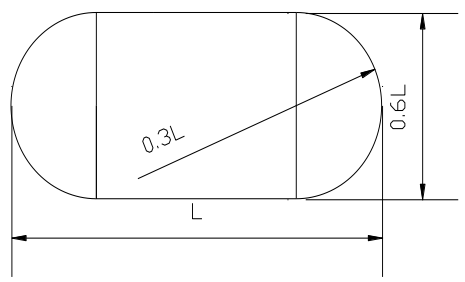

Fig. 3. Actual operating area

The effective area is reduced to a rectangular equivalent area. As shown in Figure 4, length is 0.8712 $\mathrm{L}$ and width is $0.6 \mathrm{~L}$.

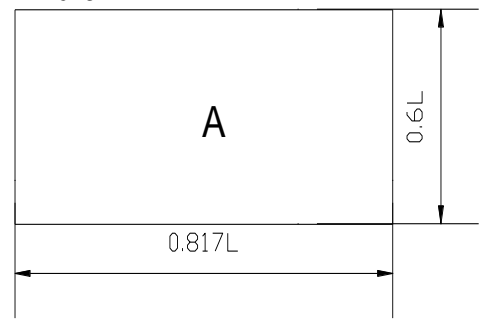

Fig. 4. Equivalent area

When two wheel loads are applied, the tire area can be equivalent to a rectangle. As shown in Figure 5, its length is the same as the rectangular length of single wheel, and its width is the center distance of two wheels. $A^{*}$ is equivalent area of two wheels. L* is equivalent rectangular length. $\mathrm{D}$ is center distance of two wheels.

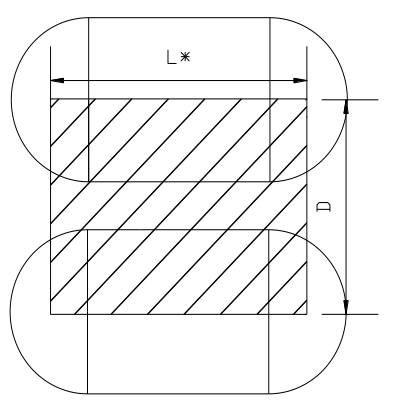

Fig. 5. Equivalent diagram of double wheel load

$$
A^{*}=\mathrm{L}^{*} \times D
$$

The vehicle load is specified in the $<$ Specifications of asphalt pavement design $>$ (JTG D50-2006). The standard axle load is BZZ-100. Double wheel axle load is $100 \mathrm{kN}$. The tyre ground pressure $\mathrm{P}$ is $0.7 \mathrm{mpa}$. The tyre ground pressure $\mathrm{p}$ is $0.7 \mathrm{mpa}$. One wheel pressure surface equivalent circle diameter $\mathrm{d}$ is $21.3 \mathrm{~cm}$. The center distance between the two wheels is $1.5 \mathrm{~d}$. The load ACTS on the center of the road surface, and the parameters related to standard load are calculated as follows. 
Single wheel area:

$$
A=\frac{F}{P}=\frac{100 / 4}{700}=357 \mathrm{~cm}^{2}
$$

Length of single wheel load:

$$
A=\frac{F}{P}=\frac{100 / 4}{700}=357 \mathrm{~cm}^{2}
$$

Equivalent acting length of two wheels:

$$
L^{*}=\frac{A}{0.6 L}=\frac{357}{0.6 \times 26.13}=22.77 \mathrm{~cm}
$$

Center distance of two wheels:

$$
D=1.5 d=21.3 \times 1.5=31.95 \mathrm{~cm}
$$

Equivalent area of two wheels:

$$
A^{*}=L^{*} \times D=22.77 \times 31.95=727.50 \mathrm{~cm}^{2}
$$

\subsubsection{Material parameter setting}

Following the rules of $<$ Specifications of asphalt pavement design $>$ (JTG D50-2006), related data of asphalt pavement design and measured value of $28 \mathrm{~d}$ modulus of compression resilience of cold regenerative mixture, the basic parameters such as elastic modulus and poisson's ratio of each layer of pavement structure are designed. Table 2 . is design parameters of pavement structure layer.

Table 2. Design parameters of pavement structure layer

\begin{tabular}{|c|c|c|c|}
\hline The structure layer & $\begin{array}{c}\text { Thickness } \\
\text { of structural } \\
\text { layer /cm }\end{array}$ & $\begin{array}{c}\text { Rebound } \\
\text { modulus } \\
\text { /MPa }\end{array}$ & $\begin{array}{c}\text { Poisson's } \\
\text { ratio }\end{array}$ \\
\hline $\begin{array}{c}\text { New asphalt } \\
\text { pavement }\end{array}$ & 8 & 1400 & 0.25 \\
\hline $\begin{array}{c}\text { Stabilized soil } \\
\text { regeneration base }\end{array}$ & $10 / 20 / 30$ & 1000 & 0.30 \\
\hline $\begin{array}{c}\text { No stabilized soil } \\
\text { regeneration base }\end{array}$ & $30 / 20 / 10$ & 1200 & 0.30 \\
\hline Original roadbed & - & 50 & 0.35 \\
\hline
\end{tabular}

\subsection{Finite element model}

When calculating pavement structure with finite element, its convergence is not only related to the reasonable division of the unit, but also related to the size of the spatial region. When the calculation range is large enough and the density degree of the element is appropriate to the field gradient, the calculation results converge to the exact solution. In the actual pavement structure, the foundation is an elastic half-space body. In order to make its infinite characteristic be reflected in the calculation, it is necessary to consider the space size range of the foundation.

Combined with the research practice in this paper, the foundation size is set as $9 \mathrm{~m} \times 9 \mathrm{~m} \times 9 \mathrm{~m}$. The model boundary condition is set as that the ground floor is fixed and the top surface is free. When the vehicle is driving in the middle of the road, there is basically no response from both sides of the road and both ends of the road. Therefore, the displacement of the corresponding direction is restrained. Fig. 6 and Fig. 7 are threedimensional finite element mesh of the model.

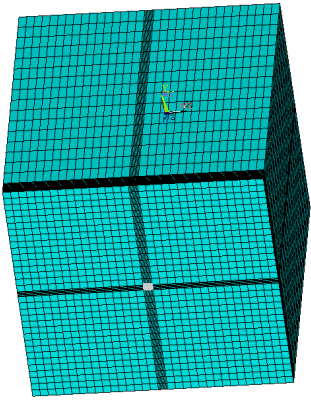

Fig. 6. Equivalent diagram of double wheel load

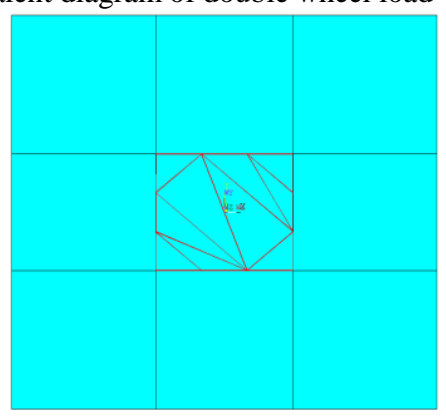

Fig. 7. Load model

\section{Finite element analysis results}

Stratified finite element simulation of XY surface shear stress, $\mathrm{Z}$ compressive stress and $\mathrm{Z}$ deformation of three types of cold regenerative pavement structures were carried out. The corresponding cloud maps are obtained. In the cloud map, the unit of stress is $\mathrm{Pa}$ and the unit of strain is $\mathrm{m}$.

\subsection{Finite element analysis of $X Y$ surface shear stress}
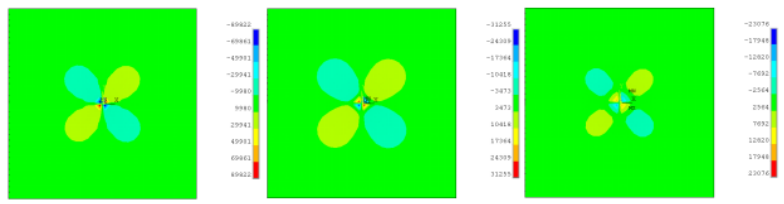

Fig. 8. The cloud map of the XY surface shear stress of the three structural layers of type 1
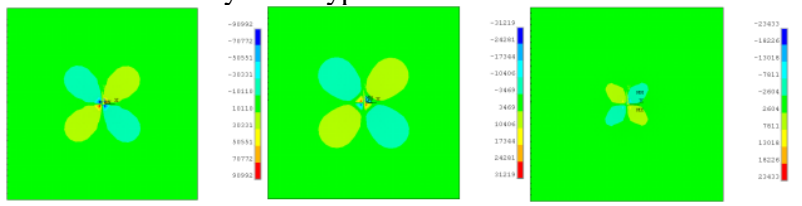

Fig. 9. The cloud map of the XY surfac eshear stress of the three structural layers of type 2
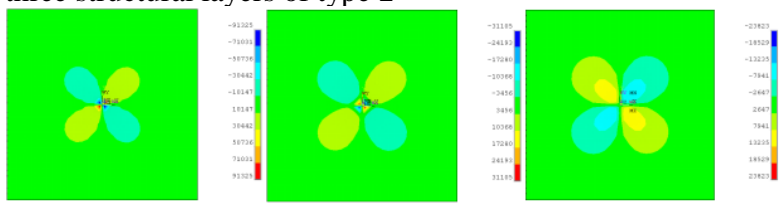

Fig. 10. The cloud map of the XY surface shear stress of the three structural layers of type 3 
Under standard axle load, Table 3 is maximum shear stress on XY surface of each structure layer. For the new asphalt surface layer and the stabilized soil regeneration base, the maximum shear stress of XY surface is in the order of type $1<$ type $2<$ type 3 . For the no stabilized soil regeneration base, the order of maximum shear stress on XY surface is type $1,>$, type $2,>$, type 3 . However, when the structure type of cold regenerative road surface changes, the maximum XY surface corresponding to each structure layer is not much different. It shows that the change of pavement structure has little effect on the maximum shear stress of XY surface of each structure layer. The resistance to shear stress on XY surface of three types of cold regenerative pavement structures is comparable.

Table 3. Maximum XY surface shear stress of each structure layer

\begin{tabular}{|c|c|c|c|}
\hline \multirow[b]{2}{*}{ Structural Layer } & Type 1 & Type 2 & Type 3 \\
\hline & \multicolumn{3}{|c|}{$\begin{array}{c}\text { Maximum XY surface shear } \\
\text { stress } / \mathrm{Pa}\end{array}$} \\
\hline New asphalt pavement & 89822 & 90992 & 91325 \\
\hline $\begin{array}{l}\text { No stabilized soil } \\
\text { regeneration base }\end{array}$ & 31255 & 31219 & 31105 \\
\hline $\begin{array}{l}\text { Stabilized soil } \\
\text { regeneration base }\end{array}$ & 23076 & 23433 & 23828 \\
\hline
\end{tabular}

\subsection{Finite element analysis of $Z$ compressive stress}
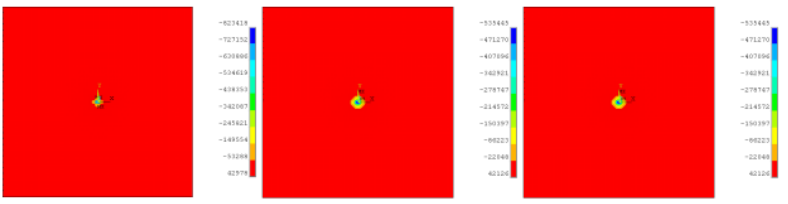

Fig. 11. The cloud map of the $\mathrm{Z}$ compressive stress of the three structural layers of type 1
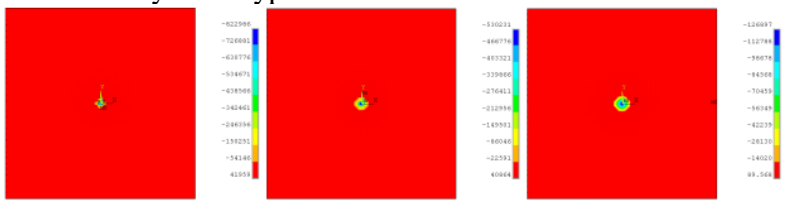

Fig. 12. The cloud map of the $\mathrm{Z}$ compressive stress of the three structural layers of type 2
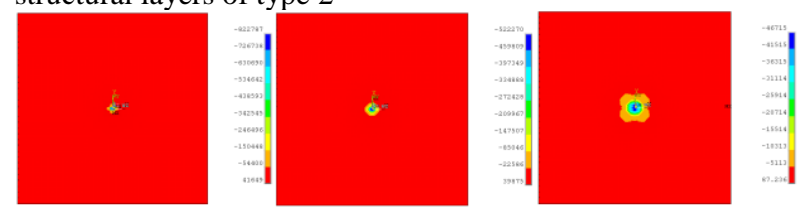

Fig. 13. The cloud map of the $\mathrm{Z}$ compressive stress of the three structural layers of type 3

Under standard axle load, Table 4 is maximum shear $\mathrm{Z}$ compressive stress of each structure layer. It can be seen that the $Z$ maximum compressive stress corresponding to the three structural layers is arranged in the order of type $1>$ type $2>$ type 3 . For the new asphalt surface layer and the no stabilized soil base, the $\mathrm{Z}$ maximum compressive stress of the three types is not much different. For the soil with stable soil base, the $\mathrm{Z}$ maximum compressive stress of type 1 is 2.15 times of that of type 2 and 5.84 times of that of type 3 . So, when the structure type of the cold regenerative pavement changes, the $\mathrm{Z}$ maximum compressive stress of the soil with stable base is greatly affected. The order of the anti$\mathrm{z}$ compressive stress capacity of the three types of cold regenerative pavement structure is type $3>$ type $2>$ type 1.

Table 4. Maximum $\mathrm{Z}$ compressive stress of each structure layer

\begin{tabular}{|c|c|c|c|}
\hline \multirow[b]{2}{*}{ Structural Layer } & Type 1 & Type 2 & Type 3 \\
\hline & \multicolumn{3}{|c|}{$\begin{array}{c}\text { Maximum } \mathrm{Z} \text { compressive } \\
\text { stress } / \mathrm{Pa}\end{array}$} \\
\hline New asphalt pavement & 823418 & 822986 & 822767 \\
\hline $\begin{array}{l}\text { No stabilized soil } \\
\text { regeneration base }\end{array}$ & 535445 & 530231 & 522270 \\
\hline $\begin{array}{c}\text { Stabilized soil } \\
\text { regeneration base }\end{array}$ & 272609 & 126897 & 46715 \\
\hline
\end{tabular}

\subsection{Finite element analysis of $Z$ deformation}
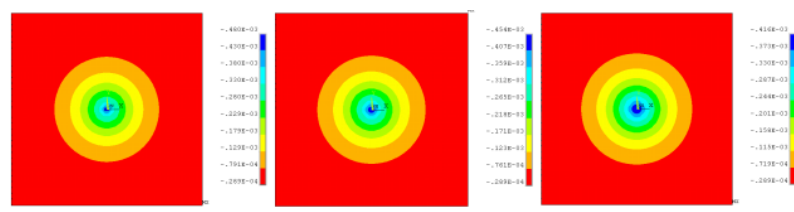

Fig. 14. The cloud map of the $\mathrm{Z}$ deformation of the three structural layers of type 1
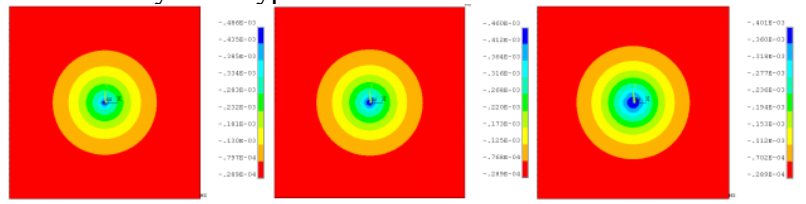

Fig. 15. The cloud map of the $\mathrm{Z}$ deformation of the three structural layers of type 2
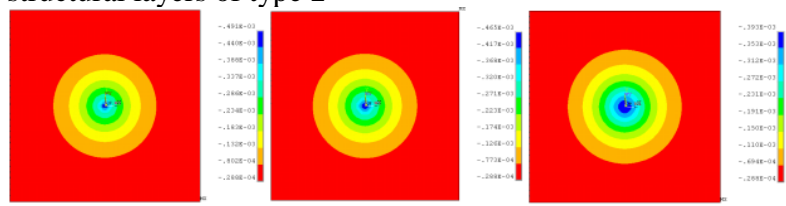

Fig. 16. The cloud map of the $\mathrm{Z}$ deformation of the three structural layers of type 3

Under standard axle load, Table 5 is maximum $\mathrm{Z}$ deformation of each structure layer. It can be seen that the for the new asphalt surface layer and unstable soil base, the size sequence of maximum $\mathrm{Z}$ deformation is type $1<$ type $2<$ type 3 . However, for the soil with stable soil base, the order of maximum $\mathrm{Z}$ deformation is type $1>$ type $2>$ type 3 .

Table 5. Maximum $Z$ deformation of each structure layer

\begin{tabular}{|c|c|c|c|}
\hline \multirow{2}{*}{ Structural Layer } & Type 1 & Type 2 & Type 3 \\
\cline { 2 - 4 } & \multicolumn{3}{|c|}{ Maximum Z deformation } \\
\hline New asphalt pavement & 0.48 & 0.486 & 0.491 \\
\hline $\begin{array}{c}\text { No stabilized soil } \\
\text { regeneration base }\end{array}$ & 0.454 & 0.460 & 0.465 \\
\hline $\begin{array}{c}\text { Stabilized soil } \\
\text { regeneration base }\end{array}$ & 0.416 & 0.401 & 0.393 \\
\hline
\end{tabular}


Taking into account the two factors of maximum $\mathrm{Z}$ deformation of each structure layer and $z$-deformation of special point with the change of pavement depth, it can be known that the size order of anti-z deformation ability of three types of cold-regenerative pavement structure types is type $1>$ type $2>$ type 3 .

\section{Conclusion}

Based on the above analysis, it can be seen that the anti$X Y$ surface shear stress of the three types of cold regenerative pavement structure is equivalent. For the ability of anti- $Z$ compressive stress and anti-Z deformation, the $Z$ compressive stress resistance of the cold-regenerative pavement structure type 1 is the worst, but the z-deformation resistance is the best. Type 3 has the best $z$-stress resistance, but the worst $z$-deformation resistance. The $\mathrm{z}$-stress resistance and $\mathrm{z}$-deformation resistance of type 2 are centered.

In order to make the cold-regenerative pavement structure anti-XY surface shear stress, anti-Z compressive stress and anti- $Z$ deformation three aspects are kept in a reasonable range. It is considered that the cold regenerative pavement structure type 2 is the best. Type 2 is specifically composed of $8 \mathrm{~cm}$ new asphalt surface layer $+20 \mathrm{~cm}$ no stabilized soil regeneration base $+20 \mathrm{~cm}$ Stabilized soil regeneration base + original road soil base. The results of this paper can provide some reference for the actual design of emulsified asphalt cold regeneration construction process.

\section{References}

1. Wang Hong, Hao Peiwen, Nan Bingzhang, Zhang Hang, Study on High Temperature Stability of Emulsified Asphalt Regenerated Mixture, Highway Engineering, 38 (2013)

2. Tood Thomas, Arlis Karmas. Performace cerelated tests and specifications for cold in-place recycling lab and field experience, TRB, (2002)

3. WEI Lian-yu, LIU Zhao-wei, ZHANG Hai-rong, WANG Jing, Experimental Analyse of Foamed Asphalt Stabilization Cold-recycled Mixture in Old Asphalt Pavement, Journal of Hebei Unicersity of Technology, 37 (2008)

4. Tood Thomas Arlis Karmas, John Huffman. Cold in-place recycling on Kansas US-283, TRB, (2000)

5. LING Tian-qing, HE Liang, MA Yu, A Cold Recycling Technique for Foamed Bitumen Mix, Journal of Civil Architectural \& Environmental Engineering, 31 (2009)

6. Xiaobo Yin, Performance of Emulsified Asphalt Full Thickness Cold Recycling Subgrade Materials, Advanced Materials Research, (2014) 